\title{
IMPORTÂNCIA DO PIB E DAS EXPORTAÇÕES SOBRE O COEFICIENTE DE ATRATIVIDADE NOS DEZ MAIORES MUNICÍPIOS DO ESTADO DO PARANÁ
}

\author{
Lorena Regina de Oliveira $^{1}$ \\ Paulo Rogério Alves Brene ${ }^{2}$ \\ Sidnei Pereira do Nascimento ${ }^{3}$ \\ Carlos Roberto Ferreira ${ }^{4}$
}

RESUMO: O presente artigo pretende estimar como as variáveis PIB e exportações afetam o coeficiente de atratividade para os dez maiores municípios do estado do Paraná. Como base de dados foi utilizada informações do IPEA, IBGE, MIDIC e RAIS, os dados foram agrupados para aplicação do modelo de regressão com o coeficiente de atratividade em função do PIB e exportações, utilizando o Coeficiente de Pearson para análise da correlação dos dados. Como resultado foi possível perceber que para os municípios de Curitiba, Maringá, Cascavel, Foz do Iguaçu, Colombo, Guarapuava e Paranaguá as duas variáveis influenciam no coeficiente de atratividade. Para os municípios de Londrina e São José dos Pinhais, apenas o PIB foi significativo. Somente Ponta Grossa as variáveis não foram significativas.

Palavra-Chaves: Economia Regional. Coeficiente de Atratividade. PIB. Exportações.

\footnotetext{
${ }^{1}$ Mestranda de Economia Regional pela Universidade Estadual de Londrina. Graduada em Ciencias Econômicas pela Universidade Estadual do Norte do Paraná.

${ }^{2}$ Doutor em Desenvolvimento Econômico. Mestre em Economia Empresarial pela Universidade Candido Mendes. Graduado em Ciências Econômicas pela Universidade Estadual de Londrina.

${ }^{3}$ Doutor em Economia pela Universidade de São Paulo. Mestre em Economia pela Universidade de Brasília. Graduação em Ciências Econômicas pela Universidade Estadual de Londrina

${ }^{4}$ Doutorado em Economia Aplicada pela Universidade de São Paulo. Mestrado em Economia Aplicada pela Universidade Federal de Viçosa. Graduação em Economia pela Universidade Estadual de Londrina.
} 


\section{INTRODUÇÃO}

O que atrai uma pessoa a se deslocar de seu espaço para outro é o tema central deste trabalho, ou seja, o que as cidades mais populosas possuem em relação às demais para atrair moradores. Castilho (2008) diz que se trata de um nicho produtivo no espaço geográfico, cujas forças estão em harmonia e se estabelece teoricamente a partir de um arranjo de competências locais com participação política, cuja melhor definição a ser dada é de ser uma região competitiva.

Para Simões (2005) um conjunto de medidas de natureza explanatória é utilizado para compreender o desenvolvimento de uma região, pode ser definidas como medidas de localização, pois está instalada em redes de fácil acesso, de fácil escoamento e solo fértil e produtivo, o que causa uma concentração no espaço na análise produtiva de cada região. Isso acarreta na disponibilidade de empregos, acesso ao saneamento básico, a escolas de qualidade, saúde a disposição e conseqüentemente um maior índice de desenvolvimento humano na região. A análise regional se defronta com o nível populacional instalado e o atrativo, pois o município oferece diversos fatores e os migrantes procuram o que irá atender a suas expectativas.

Brandt (2015) mostra que as migrações formam uma área de estudo ampla e com alto potencial de ser explorada, apresentando diversas formas de migração marcadas pelo desenvolvimento de determinadas regiões, sendo esse processo importante para compreender o modo de crescimento populacional das regiões. Nesse contexto, os diferentes ciclos econômicos do país promoveram o desenvolvimento dos eixos territoriais que se consolidaram como pólos de crescimento. As inovações e o aumento da tecnologia facilitaram a extensão de infra-estrutura pelo país, bem como a circulação de informações que possibilita o conhecimento e a mobilidade da população, ao mesmo tempo ocorreram nesses pólos profundas mudanças nos processos empresariais e de produção, o que ocasionou na atração de mão de obra qualificada.

Pode ser determinado como vantagem competitiva o PIB do município, pois ele reflete o nível de produção dessa região, seja por indústria, comércio ou prestação de serviço, a forma de analisar o PIB, como medida de atratividade, pode ser um fator determinante na escolha de uma cidade ou região para se viver. Outro ponto é as 
exportações, quanto maior as exportações de um município maior a disponibilidade de mão de obra, boas remunerações e por conseqüência um melhor ganho no bem estar humano.

No presente trabalho serão citadas diversas formas de atrair a população para municípios e regiões, porém o objetivo é criar um coeficiente de atratividade e a partir dele aplicar um modelo econométrico que possa responder ao questionamento: o PIB e as Exportações são fatores de atratividade para os municípios? Para responder a questão serão analisados os dez maiores do estado do Paraná, como base de dados será utilizada informações do IPEA, IBGE, MIDIC e RAIS para encontrar a população estimada para o período analisado, o PIB do estado bem como dos municípios estudados e as exportações do estado e dos municípios. Os dados foram agrupados para aplicação da regressão do coeficiente de atratividade em função do PIB e exportações.

O trabalho esta dividido em três sessões, desta introdução. Na primeira sessão é apresentado o levantamento teórico no qual serão explanados os diversos fatores de atratividade de um município. A metodologia que mostrará qual o método utilizado para levantamento dos dados, cálculo do coeficiente de atratividade e regressão está na segunda sessão. Já na terceira é apresentada a análise dos resultados e por fim as considerações finais.

\section{CRESCIMENTO E DESENVOLVIMENTO COMO DETERMINANTES DE ATRATIVIDADE REGIONAL}

Para Romer (1996), nos dias atuais comparados há cinqüenta anos, as implicações no padrão de vida para o bem estar humano é enorme e varia de um lugar para outro. De acordo com o autor as diferenças de renda entre países e regiões estão correlacionadas como desigualdades na nutrição, alfabetização, mortalidade infantil, expectativa de vida e outras medidas de bem estar que levam o crescimento de um determinado lugar em longo prazo. Por fim, Romer (1996) destaca que os modelos macroeconômicos tentam buscar com a maior precisão quais as variáveis que influenciam o crescimento de uma região e o porquê de outras regiões serem menos desenvolvidas. 
Lima (2010) destaca que na década de 1980 com a crise da dívida externa, houve a diminuição do papel do estado causando conseqüências consideráveis para a dinâmica econômica regional. A falta de medidas federais levou a intensa abertura comercial, essencialmente nos anos 1990, o que estimulou a desconcentração das atividades produtivas em favor da região centro-sul, assim as cidades médias passaram a desempenhar um papel estratégico, pois estas possuíam infra-estrutura necessária para desenvolver atividades produtivas sem o aumento dos custos comparados a grandes centros urbanos, os que as tornou estas regiões extremamente dinâmicas.

Andrade (2001) analisou que os moradores de grandes centros urbanos observam a cidade média como uma cidade com as características de um grande centro, mas com a tranqüilidade do interior, com menor índice de criminalidade, menos tempo para se chegar ao trabalho, menor índice de poluição, aluguéis com preços atrativos e maiores e próximas de áreas verdes. Sob a ótica dos moradores do interior aos centros médios são valorizados pela oferta de emprego, acesso a infra-estrutura básica, acesso a informação facilitada, disponibilidade educacional, enfim uma série de fatores essenciais para o crescimento da riqueza financeira e intelectual dos moradores.

Para Almeida (2009) uma região pode ser considerada desenvolvida ao se criar pólos de desenvolvimento com projetos consideráveis que se encarregaria de transbordar para os municípios que o circunda, o que pode ser oferecido qualidade de mão-de-obra, capacidade das empresas, condições institucionais, sociais, ambientais, políticas e unidades de produção.

Dessa forma, Piacenti (2012) mostrou que o desenvolvimento de uma região é bem mais do que uma breve avaliação do crescimento da renda de uma população, pois este não é um processo mecânico que pode ser estatisticamente medido com freqüência, o desenvolvimento é um processo qualitativo de mudança estrutural com essência histórica porque ajusta a evolução entre duas ou mais situações diversas. Neste contexto histórico, Piacenti (2012) mostra que o desenvolvimento econômico de uma região tem influência nos deslocamentos populacionais que se dirigem e destinam, tendo a migração como importante fator nesse processo. Ora influenciando ora sendo influenciada, para tanto existem panoramas de análise regional se constituindo e 
realizando diversas ferramentas de pesquisa de estudo socioeconômicas voltados à população.

Tratando de economia neoclássica tradicional, Arango (2004) considera a migração como simplesmente como decisões individuais de custo-benefício pensadas em maximizar o rendimento esperado com aquela região, cidade ou país. Ainda Arango (2004) determina que a renda esperada é considerada com a probabilidade de emprego vezes a renda média de determinado setor que o individuo considere trabalhar, o fluxo de mão-de-obra passa pela elevação do salário, onde as localidades que apresentam maior pagamento dse beneficiam e o contrário sofre uma pressão negativa.

No Brasil, assim como os demais países capitalistas apresenta uma forte ligação entre a migração e as oportunidades do desenvolvimento industrial e do crescimento urbano, que criam novas possibilidades no mercado de trabalho. Braga (2006) analisa que os migrantes mais qualificados caminhem para cidades mais dinâmicas no mercado de trabalho, o que culmina em melhores salários e o nível de desemprego em cidades pequenas encoraja as pessoas a caminhar em destino de cidades médias. Já para Freguglia (2010) a fuga de cérebros é um efeito regional detectado em alguns países menos desenvolvidos para os mais desenvolvidos, sendo estes beneficiados causando evidentemente o crescimento econômico maior do que em países mais pobres, o mesmo ocorre com regiões e cidades.

Além desse fato Piacenti (2012) diz que a população em geral e a migração possui intervenção pelo modo de como o desenvolvimento de uma região ocorre, e ainda a migração influencia e estimula o processo de desenvolvimento de determinada região. Cabe ressaltar que o fato de pessoas migrarem está diretamente ligado as regiões possuírem o suporte necessário aos que desejam domiciliar. E Golgher (2008), visualiza a migração como causa de conseqüências econômicas e sociais aos indivíduos e as regiões, a migração muda o quadro de faixa etária aumentando a população jovem da cidade de destino e aumentando a população idosa da cidade de origem, mostrando uma relação negativa entre a cidade e a tendência a migrar.

Um dos primeiros autores a padronizar o modelo de mobilidade social foi Ravenstein em 1885, que deu origem ao modelo atração-repulsão, citado por Aires 
(2016), a atração é determinada pelos fatores positivos que atraem a população residente em outras localidades e a repulsão é causada pelos fatores negativos que afastam a população deste lugar. O fator que determina a escolha do local de origem são os pontos negativos que afastam a população de determinado lugar, que normalmente são os de classe econômica, aos que buscam crescimento profissional e salarial. Ainda Aires (2016) aponta que o resultado do trabalho de Ravenstein conclui que inicialmente o fluxo populacional ocorre em curtas distâncias, posteriormente de regiões pequenas para as mais populosas e finalmente as de poucas oportunidades para as com maior desenvolvimento econômico e social, mostrando que como ser racional o ser humano busca maximizar suas vantagens e minimizar o inapropriado.

Piacenti (2012) indica que a análise espacial das regiões está diretamente ligada à atratividade populacional, pelo modo que os espaços se relacionam, as localizações das atividades produtivas e até como são tomadas as decisões de produção destas regiões. Piacenti (2012) ainda cita que na análise espacial um sistema é um composto de elementos e suas relações, sua aplicação está nos lugares (cidades, regiões ou territórios) e as relações com outros lugares (cidades, regiões ou territórios). Assim o potencial de aglomeração contribui para entender a origem das relações entre um conjunto de lugares no espaço regional.

Para Martins (2016) as ações espaciais e setoriais do emprego no Brasil podem ser evidenciadas a partir de três principais fatores: Políticas públicas de incentivos fiscais e de investimentos produtivos e de infra-estrutura, difusão de novas tecnologias eletrônicas e por conseqüência a reestruturação dos processos produtivos e melhorias na composição de oferta de produtos da região que ocorre dado à demanda. Ainda Martins (2016) define que esses três fatores estão ligados diretamente no crescimento de um lugar, pois existe a necessidade de políticas públicas aplicadas à industrialização nos setores principais e que exista um cenário favorável ao empresário, deste modo a criação de posto de trabalho que gerará renda será conseqüência do processo.

O potencial de atratividade pode estar ligado também às características particulares do local, atribuindo valor para estas colocando aquela cidade, região em um ranking de preferências. Um local com atrativos representados por elementos fortes 
pode reconhecer as diferenças existentes, priorizando por espaços que apresentam mais vantagens para si. Oliveira et al (2011), indica uma relação precisa entre a distância percorrida e a atratividade, quanto maior for a distância percorrida para chegar a determinado local mais apreciável tem de ser seus atrativos. Mesmo com o potencial de atratividade atribuído ao local variar consideravelmente segundo observadores, ele tende a apresentar opiniões semelhantes de um mesmo grupo.

Nos trabalhos de Walter Christaller, citado por Almeida et al. (2009), a teoria dos lugares centrais determina que a economia difere de um lugar para outro, apresentando maior ou menor grau de desenvolvimento conforme a sua localização ou distância de grandes centros, tratando a economia regional e espacial como referências para distâncias geográficas, interdependências entre municípios, o custo de transporte de insumos primários e de bens de capital. Saindo da hipótese de que os lugares com desenvolvimento econômico seguem uma hierarquia de acordo com uma rede que naturalmente tende a centralização. Almeida et al. (2009) indica que a reunião de oferta e serviços não pode ser explicada apenas por fatores geográficos, como foi constatado por Christaller, mas a distância é denominada distância econômica, pelo fato de depender custos necessários para que a mercadoria chegue a determinado lugar.

Por estes fatos mencionados acima, o trabalho pretende destacar os principais municípios do estado do Paraná, representados por quantidade populacional, e verificar se estes fatores mencionados são influenciados ou não para atrair mais pessoas para estes municípios, na tabela 1 é possível observar o ranking com os dez maiores municípios do estado do Paraná, tendo como base a estimativa do IBGE para o ano de 2016.

Ainda é válido mencionar os índices de desenvolvimento que determina a qualidade de vida dos moradores de um lugar é fator determinante no grau de atratividade para os municípios, regiões. Segundo o PNUD, o Índice de Desenvolvimento Humano (IDH) é composto por três requisitos mais importantes para expansão da liberdade das pessoas: oportunidade de vida longa e saudável, saúde, educação e renda. Segundo o PNUD, o índice pretende avaliar o bem estar e atendimento as necessidades básicas, é medido por uma escala entre 0 e 1 , onde quanto mais próximo de 1 maior o desenvolvimento humano do município. 
Tabela 1 - Ranking das maiores cidades do Paraná

\begin{tabular}{l|l|l}
\hline \multicolumn{1}{|c|}{ Município } & População \\
\hline 1 & Curitiba & 1893997 \\
2 & Londrina & 553393 \\
3 & Maringá & 403063 \\
4 & Ponta Grossa & 341130 \\
5 & Cascavel & 316226 \\
6 & São José dos Pinhais & 302759 \\
7 & Foz do Iguaçu & 263915 \\
8 & Colombo & 234941 \\
9 & Guarapuava & 179256 \\
10 & Paranaguá & 151829 \\
\hline
\end{tabular}

Fonte: Próprio autor com base no IBGE Censo (2016)

Segundo o de desenvolvimento do PNUD (2010), outros dados que denota a atratividade do município são a demografia e saúde, que determina a probabilidade de sobrevivência que é a esperança de vida ao nascer, mortalidade infantil e fecundidade, além de observar a estrutura etária da população, fatos esses que mostram a qualidade de vida da população estabelecida. Pensando em qualidade de vida, a educação faz partes dos blocos comparáveis do IDH, analisam indicadores do grau de analfabetismo e grau de escolaridade, o que determina a qualidade do conhecimento e mão-de-obra capacidade que o lugar é capaz de gerar. Já mencionado anteriormente, a renda faz parte dos atrativos de uma região e também compõe o IDH, analisando o nível de renda, de pobreza e desigualdade de renda.

O atlas de desenvolvimento do PNUD (2010) destaca outros fatores que determinam o grau de atratividade já mencionado anteriormente por outros autores, como o trabalho que determina os indicadores de atividade e desocupação; a habitação que determina pontos como característicos da habitação e acesso a serviços básicos como água, energia elétrica, esgoto, lixo; a vulnerabilidade determina à parte da população que estão vulneráveis a pobreza e depende de idosos para sobrevivência, pessoas de 15 a 25 anos que não estudam e nem trabalham, pessoas que vivem de fato com dificuldades e na pobreza. A quantidade de pessoas que reside no município e que são economicamente ativas, ou seja, os que estão ocupadas no mercado de trabalho determinam o quão atrativo ele é, pois compõe o fator ocupação nesse indicador.

Dessa forma, todos esses fatores compõem o desenvolvimento humano de um determinado lugar, esses fatores são medidos através de índices e subíndices relativos 
à Renda, Educação e Longevidade, sendo eles: IDHM - Índice de Desenvolvimento Humano Municipal; IDHM Renda - Índice de Desenvolvimento Humano Municipal na dimensão Renda; IDHM Longevidade - Índice de Desenvolvimento Humano Municipal dimensão longevidade; IDHM Educação - Índice de Desenvolvimento Humano Municipal dimensão educação. Assim, pode ser considerado um fator de atratividade os municípios que possuem um expressivo IDH.

Segundo o IBGE, o PIB é definido como o produto ou valor adicionado gerado no território econômico de um país ou região por residentes, obtidos em valores correntes, através de estimativas, determinando o valor adicionado das operações agropecuárias, da Indústria, dos Serviços, da Administração Pública e a participação dos impostos sobre produto, podendo analisar o desenvolvimento ou queda de determinado seguimento e assim analisar as situações que o circundam para melhorar o desempenho do local.

Em um recente trabalho Matos (2007) analisa algumas associações entre migração e crescimento do PIB, agrupando três conclusões: I) a agropecuária e a agroindústria tendem a se estabilizar e ampliar sua geração de riqueza, no período de 1999 a 2003 foi o setor que mais acumulou resultados positivos e tende a ser um estável gerador de divisas; II) a indústria por se estabelecer em municípios dotados de transporte, infra-estrutura e ambiente institucional favorável, o setor apresentou um crescimento significante fora dos grandes centros absorvendo as vantagens dos conglomerados; III) estimulado pelos setores mencionados, o de serviços atrai pessoas qualificadas e não qualificadas agregando salários baixos e altos. Podendo relacionar estes três pontos formadores que atraem migrações para os municípios dado o percentual do seu PIB.

Negri (2006) mostrou que entre 1994 e 1998 na fase de estabilização econômica brasileira, o regime de cambio foi sustentado em razão ao forte ganho de produtividade conhecido pelo país na época, possibilitando um desempenho razoável das exportações nesse período. Assim as exportações representaram para um país um excelente ganho de produtividade, mostrando que ela serve como escoamento para 0 
excedente ao mercado doméstico, ganhando peso às regiões que possuem potencial exportador.

Como já mencionado, a população é atraída à determinada região pela qualidade de vida, bons empregos e salários, etc. Outros fatores são válidos para analisar a questão dos municípios exportadores. Brandt (2015) apresentou um exemplo é o caso de Minas Gerais, que é o principal produtor e exportador de café do país, com isso foi necessário para a região sul do estado investimentos em infra-estrutura como armazéns, porto seco, cooperativas e com isso agregou uma das dez maiores empresas exportadoras do país, fazendo com que os trabalhadores migrassem para esta região em busca de melhor nível de vida. Outro caso é mostrado por Guida (2010) da região do Rio do Pardo no Rio Grande do sul, ela é conhecida por ser a principal área de produção, agro industrialização, comercialização e exportação de fumo em folha no país, se destacando tanto em produtividade como em qualidade na produção, o que vem apresentando ao longo dos anos um crescimento populacional devido a migração, por ofertarem empregos ligados direta ou indireta a exportação de fumo.

Dados os fatores levantados referentes à atratividade de pessoas aos municípios, será analisada qual a influência do PIB e das exportações nos maiores municípios do estado do Paraná e se eles influenciam ou não na atratividade das pessoas.

\section{METODOLOGIA E BASE DE DADOS}

Nas regiões há lugares (cidades ou microrregiões), que de acordo com Piacenti (2012), o fluxo de compras e vendas é mais forte, ou melhor, relativo a outros locais regionais, caracterizando como regiões polarizadas, onde a potência do fluxo interno é superior aos fluxos externos. Em sua essência, o índice original utilizado é o valor de compras, com os impostos recolhidos na movimentação das mercadorias e serviços ou o emprego por ramo de atividade econômica que também corresponde ao dinamismo econômico de um determinado lugar.

Ainda de acordo com Piacenti (2012), normalmente, o crescimento do fluxo comercial é retratado pelo aumento da arrecadação dos impostos ligados a transações comerciais, da mesma maneira, uma economia em crescimento tende a criar mais 
empregos e atrair a população desocupada. Suponha-se que $j$ e $i$ como dois espaços unidos e próximos (duas, cidades, duas regiões, uma cidade e uma região), o Coeficiente de Atração (CA) mede as áreas de atração e é estimado conforme apresentado pela equação 1 .

$$
C A_{j}=\frac{\left(A_{j} / \sum A_{j}\right)}{\left(\rho_{j} / \sum \rho_{j}\right)} .
$$

Onde, baseando na metodologia de Piacenti (2012) $A_{j}$ representa para esse trabalho o montante de empregos, mas, por exemplo, poderia ser o montante em valor dos impostos recolhidos pelos habitantes da cidade $i$ (ou região) na microrregião j; ou o a massa salarial total nas atividades econômicas da cidade i (ou região) na macrorregião j; a população é representada por $\rho_{i}$, população da cidade i (ou macrorregião). Assim quando um coeficiente de atração ficar entre 0 e 100 a atração de i em relação a j é fraca; entre 100 e 200 é considerada uma média atração e superior a 200 a atração entre os municípios e forte.

Como mencionado, o Coeficiente de Atratividade (CA) é definido como a razão entre o total de empregos gerados nos dez maiores municípios do estado do Paraná (Tabela 1) para o período de 1999 a 2010 e os gerado no estado do Paraná para os mesmos anos, dividido pela razão da população estimada para o município bem como a população estimada no estado Paraná na mesma série temporal. Em resumo, utilizando Piacenti (2012) o CA dos municípios estudados será analisado pela ótica do emprego.

Com os CA's calculados, serão confrontadas com a participação dos respectivos PIB e as participações das exportações de cada município. Com essa circunstância será utilizando como referência Gujarati (2011), realizando uma análise de regressão múltipla por meio de um modelo econométrico para pesquisar qual a relação que o coeficiente de atratividade $\left(\mathrm{Y}_{\mathrm{i}}\right)$, encontrado para o município tem com o PIB municipal $\left(X_{1 i}\right)$ e as exportações municipais $\left(X_{2 i}\right)$, sendo destacada na equação 2 , ou seja, o coeficiente de atratividade será a variável dependente e o PIB municipal e as 
exportações municipais as variáveis explanatórias e analisar o resultado da relação linear entre elas.

$$
Y_{i}=\beta_{1}+\beta_{2} X_{1 i}+\beta_{3} X_{2 i}+\mu
$$

Na equação o $\mu$ é conhecido como distúrbio ou termo de erro, que é uma variável aleatória que possui propriedades probabilísticas e conhecidas. $O \beta_{1}$ é o termo de intercepto ou constante, conforme a prática fornece a média sobre a variável dependente em relação as demais variáveis do modelo. Como sua interpretação pode ser automática o valor médio da variável dependente $\left(Y_{i}\right)$ quando os valores das vaiáveis independentes $\left(\mathrm{X}_{1 \mathrm{i}}\right)$ e $\left(\mathrm{X}_{2 \mathrm{i}}\right)$ forem igualadas a zero. Gujarati (2011) supõe que essa relação linear seja exata ou determinística, mas as relações entre as variáveis econômicas são inexatas, estando sujeita a mudanças individuais. Com o levantamento feito anteriormente foi possível analisar diversos fatores que atraem as pessoas para um determinado município entre eles emprego, renda, acesso a tecnologia e cultura, e todos esses fatores só serão apresentados se os municípios tiverem um PIB alto, ou seja, produzindo e comercializando a produção e uma exportação considerável, pois esta gera impostos consideráveis que são convertidos ao município.

Dada a relação entre o PIB e as exportações $(P I B=C+I+G+X-M)$ tem-se a preocupação com o problema da Multicolineariedade (mesmo sendo calculadas com participações relativas). Para Gujarati (2011), Multicolinearidade originalmente significa a persistência de uma perfeita ou exata relação linear entre variáveis (algumas ou todas as variáveis) explicativas de um modelo de regressão, levando a coeficientes estimados com pouca precisão. Continuando, Gujarati (2011) diz que a Multicolinearidade pode ser causada pelo modo em que os dados formam coletados como uma amostra limitada de valores pelos repressores da população; restrições sobre o modelo ou população analisada, por exemplo, como a restrição do tamanho da casa para o consumo de energia elétrica; se o pesquisador adicionar termos polinomiais ao modelo terá uma especificação do modelo principalmente em uma pequena amostra; quando o modelo possuir mais variáveis explicativas que o numero de observações causará um modelo sobre determinado, fato que pode ocorrer em pesquisas médicas com um pequeno número de pacientes sobre informações de muitas variáveis. 
Desta forma destaca-se que o coeficiente de Pearson (rp) é descrito, segundo Lira e Chaves Netas (2006), como um indicador que analisa a interdependência entre duas variáveis. Já para Moore (2007, p. 100/101) “(...) o coeficiente de correlação de Pearson ( $r$ ) é uma medida de associação linear entre variáveis". Nessa linha, de acordo com Filho (2009), o coeficiente de Pearson varia de -1 a 1 , onde, o sinal indica a direção do relacionamento e o valor demonstra a força da relação entre as variáveis, portanto, ainda segundo o autor, uma correlação perfeita (-1 ou 1) "(...) indica que o escore de uma variável pode ser determinado exatamente ao se saber o escore da outra". Sendo assim, uma correlação de valor zero indicará o contrário, ou seja, que não existe relação linear entre as variáveis. Para se classificar qualitativamente, será utilizada a escala de Callegari Jacques (2003, p. 90), onde: se $0,0<\mid$ rp $\mid<0,3$, observa-se fraca correlação linear; se $0,3 \leq|r p|<0,6$, observa-se moderada correlação linear; se 0,6 $\leq|r p|<0,9$, observa-se forte correlação linear; se $0,9 \leq|r p|<$ 1,0 , observa-se correlação linear muito forte. Com isso, quanto mais perto de 1 , independente do sinal, maior é o grau de correlação entre as variáveis e quanto mais perto de zero, menor é a força da mesma.

A RAIS (2017) foi utilizada para levantar os dados referentes ao emprego das cidades bem como do estado do Paraná, analisando o total de empregos formais gerados pelo município e estado no final de cada ano corrente. Para o PIB municipal os dados foram retirados do IPEA (2017), analisando o valor adicionado da produção no final de cada ano corrente, também não foram imunes as dificuldades nos anos disponíveis. A população foi levantada pelos dados do IBGE, através das estimativas anuais realizada pelo órgão. As exportações foram dadas pelo Ministério do Desenvolvimento o MIDIC (2017), a partir do balanço anual de pagamentos foi possível conhecer as exportações de cada município e do estado.

O período analisado consiste na adequação dos dados disponíveis nas bases juntamente com a idéia proposta pelo autor. Foi possível concentrar dados de onze anos, para que o modelo proposto fosse adequado. No geral, a regra é de analisar a maior quantidade possível de dados, podendo considerar instáveis as análises provenientes de amostras pequenas, porém amostras com grande número de dados pode aumentar a chance de causar correlação entre os dados. Hair et al (2009) sugere 
que o número de amostras nunca devem ser menores do que cinco para cada variável independente. Tabachinick e Fidell (2007) mencionam que $N \geq 50+80 X$, onde $X$ é o numero de variáveis independentes da análise. Stevens (1996) sugere aproximadamente 15 observações por variável. Dessa forma será baseado na literatura de Hair et al (2009) que sugere utilizar acima de cinco amostras.

\section{ANÁLISE DOS RESULTADOS}

Com o levantamento do referencial teórico e metodológico, é possível apresentar os resultados do modelo econométrico, onde se analisou a relação entre o CA com as variáveis PIB e exportação para os dez maiores municípios do estado do Paraná no período de 1999 a 2010, juntamente com o resultado do coeficiente de Pearson. Para o teste de hipóteses será determinada a hipótese nula $\left(H_{0}\right)$ as variáveis PIB e Exportações influenciam o $\mathrm{CA}$, e a hipótese alternativa $\left(\mathrm{H}_{\mathrm{A}}\right)$ o PIB e as exportações não influenciam o CA.

Inicialmente, o resultado da Correlação de Pearson poderá corroborar a possibilidade de existir multicolinearidade nos dados pesquisados. Como visto na metodologia quanto mais próxima de um os resultados da correlação de Pearson mais relacionada linearmente estão às variáveis, na tabela 2 temos os resultados do teste de Pearson dos dez municípios explorados.

Para Ponta Grossa, Colombo e Guarapuava que apresentaram respectivamente os resultados de $-0,13181,-0,71700$ e $-0,19436$, é considerado na metodologia da escala de Callegari Jacques (2003, p. 90) que quanto mais próximo de zero menor a relação linear entre as variáveis chegando a ser nula, dando a possibilidade das amostras destas cidades não possuírem multicolinearidade. O município de Curitiba apresentou um coeficiente de Pearson de 0,15033, concluí-se que o município apresenta uma fraca correlação linear, mostrando que a incidência multicolinearidade nesse caso é pequena. Para Maringá, e Paranaguá os resultados se encaixam na mesma escala, todos apresentaram fraca correlação linear e conseqüentemente pouca chances das variáveis se relacionarem. 
Tabela 2: Resultado do Coeficiente de Pearson

\begin{tabular}{l|l}
\hline Municípios & Resultados \\
\hline Curitiba & 0,150339581 \\
Londrina & 0,486585942 \\
Maringá & 0,139094659 \\
Ponta Grossa & $-0,131819382$ \\
Cascavel & 0,612627102 \\
S.J. dos Pinhais & 0,526073714 \\
Foz do Iguaçu & 0,511724769 \\
Colombo & $-0,717007726$ \\
Guarapuava & $-0,194367187$ \\
Paranaguá & 0,088194153 \\
\hline
\end{tabular}

Fonte: Elaboração Própria.

O resultado para Londrina foi de 0,48658 , indicando na escala moderada correlação linear, assinalando uma probabilidade maior de se detectar multicolinearidade no resultado da regressão, São José dos Pinhais e Foz do Iguaçu também está pontuado na escala de moderada relação linear entre as variáveis. Cascavel foi o município que apresentou o maior coeficiente de Pearson, com o resultado de 0,61262 que na escala de Callegari Jacques (2003, p. 90) uma forte correlação linear entre as variáveis, dando maior atenção na possibilidade da amostra apresentar multicolinearidade.

Dando continuidade a análise dos dados, serão observados na regressão amostral, conforme mencionado por (Gujarati, 2011, p.339) o coeficiente de determinação múltiplo $\left(R^{2}\right)$ que representa o quanto a variável dependente é explicada pelas explanatórias, no caso da multicolinearidade o $R^{2}$ alto (acima 0,9$)$ indica presença de correlação entre as variáveis. O teste t utiliza os resultados amostrais para verificar a veracidade da hipótese nula, uma estatística será significativa se o valor do teste t estar na região critica, rejeitando a hipótese nula, ou o teste será insignificante se o valor do teste $t$ estar na região de aceitação. Gujarati (2011, p.252) determina que o teste $F$ analisa se a distribuição é normal com média e zero e variância constante, se o $\mathrm{F}$ calculado (Fcalc) superar o valo do $\mathrm{F}$ tabelado (Ftab) ao nível de significância, rejeita a hipótese nula, caso contrário não. Na tabela 3 estão todos os resultados dos testes realizados pelos municípios. 
Tabela 3 - Resultado da Regressão para os dez maiores Municípios do Estado do Paraná

\begin{tabular}{|c|c|c|c|c|}
\hline Municípios & $\mathrm{R}^{2}$ & Teste $\mathrm{F}$ & \multicolumn{2}{|l|}{ Teste t } \\
\hline & & & PIB & EXP \\
\hline Curitiba & 0,090005 & 0,002255 & $-0,943332$ & 0,158695 \\
\hline Londrina & 0,745395 & 13,174409 & 4,556392 & $-0,151879$ \\
\hline Maringá & 0,466739 & 3,938644 & $-2,314090$ & $-1,250851$ \\
\hline Ponta Grossa & 0,746176 & 13,228802 & 3,193536 & $-3,576080$ \\
\hline Cascavel & 0,150659 & 0,798225 & $-1,255798$ & 0,659189 \\
\hline S.J. dos Pinhais & 0,609757 & 7,031280 & 3,736220 & $-1,692294$ \\
\hline Foz do Iguaçu & 0,368053 & 2,620853 & 0,004653 & $-1,692294$ \\
\hline Colombo & 0,485528 & 4,246839 & 0,689045 & $-1,479874$ \\
\hline Guarapuava & 0,464426 & 3,902201 & 2,717779 & $-0,106013$ \\
\hline Paranaguá & 0,135037 & 0,702534 & 0,871107 & 0,131768 \\
\hline
\end{tabular}

Fonte: Elaboração Própria.

Com o resultado da equação é possível fazer a análise, para Curitiba as variáveis PIB e Exportações explicam cerca de $9 \%$ do coeficiente de atratividade e não indica presença de multicolinearidade. Ao explorar o teste t, o t tabelado encontrado para as regressões foi de 2,91, comparando com o t para Curitiba se constatou que o mesmo está na região de não rejeição de $\mathrm{H}_{0}$, o determina que as variáveis PIB e Exportações influenciem no $\mathrm{CA}$, o teste $\mathrm{F}$ confirma o resultado indicando que Ftab $(4,2564)>$ Fcalc $(0,0022)$ causando também a não rejeição de $\mathrm{H}_{0}$ com um nível de significância de 5\%.

Já para Londrina, o $\mathrm{R}^{2}$ mostrou que as variáveis independentes explicam $74,63 \%$ e não está indicando multicolinearidade. No teste t a variável PIB está na região de rejeição de $\mathrm{H}_{0}$, mostrando que ela não influência no CA de Londrina, porém a Exportação está na região de aceitação de $\mathrm{H}_{0}$, mostrando que influencia no CA. $\mathrm{O}$ teste F mostrou que ambas não influenciam no CA, com um nível de significância de 5\% (Ftab $(4,2564)<$ Fcalc $(13,1744)$.

O PIB e Exportações de Maringá correspondem por 46,67\% do CA municipal e não indica presença de multicolinearidade. Com o teste $t$ foi possível mostrar que ambas variáveis estão na região de aceitação de $\mathrm{H}_{0}$ e o teste $\mathrm{F}$ concluiu a um nível de significância de 5\% que Ftab $(4,2564)$ > Fcalc $(3,9386)$, confirmando a não rejeição de $\mathrm{H}_{0}$. Porém em Ponta Grossa o resultado foi outro, mesmo as vaiáveis explicando $74,61 \%$ da variável independente e sem apresentar indicações de multicolinearidade, 0 teste $\mathrm{t}$ mostrou que ambas estão na região que rejeita a hipótese nula o que foi 
confirmado a um nível de significância de $5 \%$ pelo teste $F$, pois Ftab $(4,2564)<$ Fcalc $(13,2288)$.

Em Cascavel, o PIB e a Exportação explicam 15,06\% do CA e sem indícios de multicolinearidade. Com o teste $t$ foi possível perceber que as variáveis estão na região de não rejeição de $\mathrm{H}_{0}$, sendo essa idéia corroborada pelo teste $\mathrm{F}$ a um nível de significância de $5 \%($ Ftab $(4,2564)>$ Fcalc $(0,7882))$, mostrando que neste município o PIB e as exportações explicam o CA. Em São José dos Pinhais o caso foi diferente, pois o PIB e as Exportações explicam 60,97 do CA sem a presença de multicolinearidade, porém com o teste $t$ foi possível observar que o PIB não explica o CA (resultado na região de rejeição de $\mathrm{H}_{0}$ ), mas as exportações explicam pois estão na região de não rejeição da hipótese nula. Com o teste $\mathrm{F}$ constata-se que as variáveis não explicam o CA a um nível de significância de 5\%: Ftab $(4,2564)<$ Fcalc $(7,0312)$.

Em Foz do Iguaçu o PIB e a Exportação explicam 36,80\% do CA, sem indícios de multicolinearidade. Com a análise do teste t percebeu que seu resultado está na região de aceitação da hipótese nula e o teste $\mathrm{F}$ confirmou a idéia resultando a um nível de significância de $5 \%$ que o Ftab $(4,2564)>$ Fcalc $(2,6208)$. O mesmo ocorreu em Colombo, com um coeficiente de determinação de $48,55 \%$ mostrou como as variáveis explicativas influenciam na dependente e ainda não indicando multicolinearidade. Nos testes $\mathrm{t}$ e $\mathrm{F}$ os resultados foram o mesmo, o $\mathrm{t}$ apresentou $\mathrm{o}$ resultado na região de aceitação da hipótese nula e o F a um nível de significância de $5 \%$ que o Ftab $(4,2564)$ > Fcalc $(4,2468)$, mostrando a não rejeição da hipótese nula.

Em Guarapuava, as variáveis independentes explicam cerca de $13,50 \%$ do CA, e não apresentou indícios de multicolinearidade. Com o teste t foi possível observar que o resultado da equação está na região de aceitação da hipótese nula e o teste $\mathrm{F}$ confirma a um nível de significância de 5\% que o Ftab $(4,2564)>$ Fcalc $(3,9022)$ a não rejeição da hipótese nula. Finalizando, em Paranaguá o PIB e a Exportação explicam cerca de $13,50 \%$ do coeficiente de atratividade e não apresentou multicolinearidade, o teste $t$ mostrou que o resultado das variáveis encontram-se na região de aceitação da hipótese nula sendo este resultado reafirmado pelo teste $\mathrm{F}$ que com um nível de significância de $5 \%$ mostrou que Ftab $(4,2564)>$ Fcalc $(0,7025)$ não rejeitando $\mathrm{H}_{0}$. 
Mesmo o resultado do coeficiente de determinação não indicando presença de multicolinearidade nas amostras analisadas, o coeficiente de Pearson demonstrou um município com grau forte de correlação e três de grau moderado, para que o grau multicolinearidade seja diminuído foram feitas regressões simples para cada variável analisada nos modelos, a tabela 4 mostra os resultados da regressão simples do PIB.

Tabela 4 - Regressão Simples do PIB.

\begin{tabular}{l|l|l|l|l}
\hline \multirow{2}{*}{ Pearson } & Municípios & $\mathrm{R}^{2}$ & Teste $\mathrm{F}$ & Teste $t$ \\
\cline { 2 - 5 } & Londrina & 0,74474 & 29,1761 & 5,40149 \\
& Foz do Iguaçu & 0,08405 & 0,91768 & 0,95796 \\
MOD & S. J. dos Pinhais & 0,48558 & 9,43934 & 3,07235 \\
\hline FORTE & Cascavel & 0,10965 & 1,23156 & $-1,1098$ \\
\hline
\end{tabular}

Fonte: Elaboração Própria.

Analisando os municípios em que o coeficiente de Pearson foi maior, com a regressão simples do coeficiente de atratividade em função do PIB, o único em que o $R^{2}$ permaneceu alto foi Londrina, mas ainda estando abaixo do valor que possa indicar presença de multicolinearidade, os demais municípios mostraram que a variável não é colinear com o coeficiente de atratividade. Relativo ao teste F, o Fc $(4,9646)$ foi menor com o F dos municípios de Foz do Iguaçu e Cascavel indicando que a variável PIB individualmente influencia no coeficiente de atratividade, em Londrina e São José dos Pinhais continua indicando que essa variável não influencia no CA. A tabela 5 mostra as regressões simples do coeficiente de atratividade em função das exportações.

Tabela 5 - Regressão Simples do PIB.

\begin{tabular}{l|l|l|l|l}
\hline Pearson & Municípios & $\mathrm{R}^{2}$ & Teste $\mathrm{F}$ & Teste t \\
\cline { 2 - 5 } & Londrina & 0,158084915 & 1,877682409 & 1,370285521 \\
& Foz do lguaçu & 0,367495332 & 5,810159994 & 2,410427347 \\
MOD & S. J. dos Pinhais & 0,004475816 & 0,044959389 & 0,212036292 \\
\hline FORTE & Cascavel & 0,001832835 & 0,018362004 & $-0,135506473$ \\
\hline
\end{tabular}

Fonte: Elaboração Própria.

Londrina, São José dos Pinhais e Cascavel, apresentaram redução no $R^{2}$, indicando uma diminuição no grau de multicolinearidade para a variável exportação, Foz do Iguaçu apresentou pequena queda comparada com a Regressão múltipla, porém seu valor já era baixo, indicando pouca probabilidade de multicolinearidade. No teste $\mathrm{F}$, o Fc foi maior apenas para Foz do lguaçu, indicando que as exportações não 
influência no CA e influenciando para os demais municípios. Para o teste $t$ todos os municípios estão na região de aceitação de que a variável exportação influência no seu CA.

\section{CONSIDERAÇÕES FINAIS}

O objetivo inicial do trabalho era compreender através de um modelo econométrico o que levam as pessoas de um lugar para outro, se o fator migração poderia ser medido por alguma variável. Com esse questionamento o pesquisador foi levado até o coeficiente de atratividade, medida que pode dar valor a atração populacional de determinada região. Com o levantamento teórico foi encontrado que as pessoas buscam empregos e salários melhores, uma qualidade de vida satisfatória, educação de qualidade, e outros fatores que enquadram na medida do PIB, andam apontou que regiões com grandes empresas atraem mais pessoas, com isso aumentam a produção caminham rumo às exportações.

Com esses fatos em mãos, foi elaborado um modelo de regressão linear através do Método dos Mínimos Quadrados Ordinários, que poderia analisar se o coeficiente de atratividade (variável explicada) possui influência sobre o PIB e as exportações (variáveis explicativas), com isso foram escolhidas as dez maiores cidades do estado do Paraná em população e obtido os dados através de órgãos como o IPEA, IBGE, MIDIC.

Com os resultados da regressão e a análise de Pearson foi possível concluir que o coeficiente de atratividade pode ser explicado pelo PIB e as exportações para os municípios de Curitiba, Maringá, Cascavel, Foz do Iguaçu, Colombo, Guarapuava e Paranaguá. Já os municípios de Londrina e São José dos Pinhais o teste t indicou que o CA é explicado somente pela variável Exportação, o PIB não explica o CA municipal, o teste $\mathrm{F}$ indicou que ambas as variáveis não explicam o $\mathrm{CA}$, podendo ser um indicio de multicolinearidade. Somente Ponta Grossa indicou que ambas as variáveis não explicam seu CA. Na regressão simples, analisando as variáveis individuais para os municípios que apresentaram maior coeficiente de Pearson, foi possível perceber que para o PIB e exportações no teste $t$ todos mostraram que exercem alguma influência no coeficiente de atratividade e reduzindo o grau de multicolinearidade dos testes. Outro 
fato que chamou a atenção foi o de vários resultados do teste t aceitar a hipótese nula, fato que pode culminar na multicolinearidade.

Os resultados geram parâmetros para novos trabalhos, buscando compreender os casos de Londrina e São José dos Pinhais e qual a possibilidade de outras variáveis comporem o modelo de regressão e o caso de Ponta Grossa a de decifrar quais as vaiáveis que explicam o seu coeficiente de atratividade, ainda combinar outros fatores de atratividade buscando diminuir a correlação das variáveis analisadas. Abre preceitos também para entender se combinadas com outras variáveis quais seria o coeficiente de atratividade destes municípios.

\section{REFERÊNCIAS}

AIRES, Regina Paula Dias Jesus. Capacidade de atração/repulsão de população nos municípios do Oeste: Medição, fatores determinantes e importância para a sustentabilidade do crescimento econômico. Tese Mestrado em Economia Departamento de Economia, Universidade de Coimbra. Coimbra, 2016.

ALMEIDA, André Martins. Cálculo do Índice de Atratividade (IA) para os Municípios da Amusep com Baixo Índice de Desenvolvimento Regional (IDR). São Paulo: VI Seminário da Associação Brasileira de Pesquisa e Pós-Graduação em Turismo, UAM, 2009.

ANDRADE, T. A.; SERRA, R. V. (Org.). Cidades médias brasileiras. Rio de Janeiro: IPEA, 2001.

ARANGO, Joaquin. Theories of international migration. In: JOLY, Danièle (Ed.) International migration in the new millennium, Ashgate, Inglaterra, 2004.

PNUD. Atlas de desenvolvimento humano <http://www. atlasbrasil.org.br> Publicado após o senso de 2010. Acesso em 14 de Fevereiro de 2017.

Base de dados Regional. PIB Municipais Valor Adicionado

<http://www.ipeadata.gov.br> Acesso em 16 de Fevereiro de 2017.

BRAGA, F. G. Migração Interna e Urbanização no Brasil Contemporâneo: Um estudo da Rede de Localidades Centrais do Brasil (1980/2000). In: ENCONTRO NACIONAL DE ESTUDOS POPULACIONAIS, 15. Anais: Caxambu, set. 2006.

BRANDT, Graziele B.; SILVEIRA, Rogério L. L.; Migração e região: análise do perfil dos migrantes no corede do Vale do Rio do Pardo (RS). Santa Cruz do Sul: VII Seminário Internacional de Desenvolvimento Regional, UNISC, 2015. 
CASTILLO, R. A. Região competitiva e logística: expressões geográficas da produção e da circulação no período atual. Santa Cruz do Sul: IV Seminário Internacional sobre Desenvolvimento Regional, UNISC, v. 1. 2008.

Comércio Exterior. Exportações <http://www.mdic.gov.br/> Acesso em 16 de Fevereiro de 2017.

FEGER, J. E.; NODARI, L. D. T.; LANZZAROTTI, F.; Método da correlação de variáveis para a previsão da demanda turística: uma aplicação visando o planejamento do desenvolvimento turístico em uma região sul brasileira. Caderno Virtual de Turismo. Rio de Janeiro, v. 11, n. 3, p.294-307, dez. 2011.

FERRONATO, M.Z.; CARDOZO, P.F. Criação de uma nova metodologia de avaliação e hierarquização: estudo de caso no município de Irati-Pr. Irati: Partes revista virtual, 2010.

FILHO, Dalson B. F. \& Silva Júnior, J. A. Desvendando os Mistérios do Coeficiente de Correlação de Pearson (r). Revista Política Hoje, Vol. 18, n. 1, p. 1--15 2009.

FREGUGLIA, Ricardo.; GONÇALVES, Eduardo.; FAJARDO, Bernardo.; TAVEIRA, Juliana. Determinantes da Mobilidade de trabalhadores qualificados em municípios do estado de São Paulo (1999-2002). UFJF, Pós-Graduação em Economia Aplicada, 2010.

GOLGHER, A. B. As cidades e a classe criativa no Brasil: diferenças espaciais na distribuição de indivíduos qualificados nos municípios brasileiros. Revista Brasileira de Estudos da População, v. 25, p. 109-129, 2008.

GUIDA, Larissa Chiulli. As cidades do Agronegócio do sul de minas: a constituição de Muzambinho como uma cidade funcional à produção cafeeira. Rio Claro: I Congresso brasileiro de organização de espaço, UNESP, 2010.

GUJARATI, Domodar N. Econometria Básica. São Paulo, Ed. Mac Gral Hill, 2011.

HAIR, Jr.; ANDERSON, Ralph; TATHAM, Ronald; BLACK, Willian. Multivariate data analysis. Ed. Prentice Hall, 17ª Edição, 2009.

LIMA, Ana Carolina Cruz.; SIMÕES, R.; HERMETO, Ana Maria. Desenvolvimento regional, hierarquia urbana e condições de migrações individuais no Brasil entre 1980-2010. Rio de Janeiro: UFRJ, 2010.

LIRA, S. A.; CHAVES NETO, A. Coeficientes de correlação para variáveis ordinais edicotômicas derivados do coeficiente linear de Pearson. RECIE, Uberlândia, v. 15, n.1/2, p. 45-53, jan. dez. 2006. 
MATOS, R.; GARCIA, R. A. Novos espaços da migração ou espaços efêmeros do emprego e da população. Campinas: Encontro sobre migrações, Unicamp, 2007.

MARTINS, D. B.; JUNIOR, Pedro Cardoso B.; LIMA, Fernanda Cruz. Identificação dos municípios dinâmicos no setor agropecuário no estado do Amapá. João Pessoa:

Encontro Nacional de Engenharia da Produção. 2016.

NEGRI, João Alberto.; ARAÚJO, Bruno C.P.O.(Org.) As empresas brasileiras e o comércio internacional. Brasília, IPEA, 2006.

OLIVEIRA, lana Cavalvante. A hierarquização dos atrativos naturais do município de Presidente Figueiredo no Estado do Amazonas. Rio de Janeiro: UFRJ/COPPE, 2011.

PIACENTI, C. A. FERRERA, Lima J. ALVES, L. R. PIFFER, M.; RIPPEL, R. Análise Regional: metodologias e indicadores. Curitiba, Camões, 2012.

População. Projeção da População <http://www.ibge.gov.br/> Acesso em 12 de Fevereiro de 2017.

RAIS. Estabelecimentos <http://bi.mte.gov.br/bgcaged/login.php> Acesso em 15 de Fevereiro de 2017.

ROMER, David. Advanced Macroeconomics. MacGraw-Hill, 1996.

SIMÕES, Rodrigo Ferreira. Métodos de Análise Regional e Urbana: diagnóstico aplicado ao planejamento. Belo Horizonte: UFMG, Cedeplar, 2005.

STEVENS, James. Applied Multivariate Statistics for the social sciences. $3^{\mathrm{a}}$ Ed. Mahwah, Nj. Lawerence Erlbaum Associeates, 1996.

TABACHINICK, Barbara; FIDELL, Linda. Using multivariate analysis. Needham Heights, Allyn e Bacon, (2007). 